\title{
Dietary supplement use among a population of university students in Italy: Correlations with BMI, dietary habits and sport activities
}

\author{
Traversi Deborah ${ }^{1,}$, Gorrasi Ilaria ${ }^{1}$, Galis Veronica ${ }^{1}$, Biorci Felicina ${ }^{2}$, Siliquini Roberta ${ }^{1}$, \\ Gilli Giorgio 1 \\ ${ }^{1}$ Department of Public Health and Paediatrics, Università di Torino UNITO, piazza Polonia 94, 10126, Turin, Italy \\ ${ }^{2}$ Centro di Medicina Preventiva e dello Sport SUISM, Piazza Bernini 12, 10100 Turin, Italy
}

\section{Email address:}

deborah.traversi@unito.it (T. Deborah), ilaria.gorrasi@unito.it (G. Ilaria), veronica.galis@unito.it (G. Veronica), felicina.biorci@unito.it (B. Felicina), roberta.siliquini@unito.it (S. Roberta), giorgio.gilli@unito.it (G. Giorgio)

\section{To cite this article:}

Traversi Deborah, Gorrasi Ilaria, Galis Veronica, Biorci Felicina, Siliquini Roberta, Gilli Giorgio. Dietary Supplement Use among a Population of University Students in Italy: Correlations with BMI, Dietary Habits and Sport Activities. International Journal of Nutrition and Food Sciences. Vol. 3, No. 2, 2014, pp. 73-78. doi: 10.11648/j.ijnfs.20140302.19

\begin{abstract}
Attention to personal health and to healthy lifestyles has increased in recent decades among the population of industrialised countries. Various phenomena are linked to this change, such as the proliferation of fitness and wellness centres, the increased consumption of organic food and the extended use of dietary supplements. Food supplementation has become popular, as has the attention to the nutritional aspects of dietary behaviour. The use of dietary supplements is generally more common between people with higher socioeconomic status, healthier lifestyle habits, higher education level and lower body mass index (BMI), furthermore is more common in women than in men. In this study we aimed to investigate the prevalence of use of food supplements in a group of university students, correlating the use with indicators of healthy lifestyles generally associated with the consumption, such as BMI, dietary habits and sport activity. Data were collected through a self-administered questionnaire filled out by 145 voluntary students, attending the university in the city of Turin, North of Italy, belonging to areas of sport, biologic and medical sciences. The questionnaire included questions related to personal information, dietary attitudes and supplement consumption. $45.1 \%$ of the students reported the use of supplements. Vitamins/minerals and sport supplements were the most commonly consumed and were taken mainly to improve sport performance or to improve health. No relevant differences between supplement consumers and non consumers were seen in relation to healthy behaviours and to gender or anthropometric characteristics, except for a lower BMI in male supplement consumers and a higher consume of specific sport supplements in male with very intense sport activity.
\end{abstract}

Keywords: Dietary Supplements, Consumption Survey, Dietary Behaviour, University Population

\section{Introduction}

Dietary fortification with micronutrients is a recent and important issue, intended particularly to provide nutritional elements useful for preventing diseases, maintaining a good status of health [1] or for supply ready-to-use resources for sporting activities [2]. According to United States regulations, the term "dietary supplement" refers to a product that contains one or more of the following ingredients: vitamins, minerals, herbs or other botanicals, amino acids, dietary substances that supplement the human diet by increasing the total dietary intake, concentrates, metabolites, constituents and extracts [3]. In the European legislation, Directive 2002/46/EC of the European Community, dietary supplements are defined as concentrated sources of nutrients or other substances with a nutritional or physiological effect whose purpose is to supplement the normal diet.

Dietary supplement use is increasingly common in developed countries. Data from the National Health and Nutrition Examination Survey shows that among the U.S. adult population, the percentage who uses at least one dietary supplement has increased from $42 \%$ in the period 1988-1994 to 53\% in 2003-2006 [4]. A study conducted in South Korea in 2006 indicates that $55.9 \%$ of men and $68.9 \%$ 
of women had consumed some dietary supplements in the previous twelve months [5]. In Europe, data related to period 1995-2000 shows wide variations in the use of supplements, with a clear north-south gradient and a higher consumption in northern countries. The greater crude mean percentage was registered in Denmark $(51.0 \%$ men, $65.8 \%$ women), while in Italy only $6,8 \%$ of men and $12,6 \%$ of women reported to consume supplements. However, a recent survey reports that approximately $50 \%$ of Italians consume dietary supplements, especially young adults [6]. Other studies on adult populations shows a percentage of consumption of $26 \%$ in Switzerland [7] and of 9,3\% in Spain [8]. Both in USA and Europe the consumption is higher in women than in men [9]. The prevalence of supplement consumption increases in specific target subpopulations such as the elderly, those affected by particular diseases, pregnant women and those involved in sports [5, 10-13]. Several epidemiological studies correlates supplement use with people with higher socioeconomic status, healthier lifestyle habits, higher education level and lower BMI [14-16]. In Italy, a recent study reports dietary supplement use among $30 \%$ of its fitness centre attendees [17]. Some studies performed on university students found a supplement use prevalence ranging from 10 to $49 \%$ [18-20]. The aim of our study was to investigate the diffusion of the use of dietary supplement in a specific subgroup of young adults, constituted by university students, in Turin, Italy, evaluating the association with BMI and healthy behaviours like sport activities and dietary habits.

\section{Materials and Methods}

In this preliminary survey, approximately 180 students who attended the first year at the University were initially invited to participate in the study: the $80 \%$ accepted, so 145 students were included in the project. Students belonged to three different university divisions: $55 \%(\mathrm{n}=79)$ attended the School of Sport Sciences (SUISM), 31\% $(n=45)$ the School of Mathematics, Physics and Natural Sciences (MPN Sciences) (which includes Biological Sciences) and $14 \%(n=20)$ the School of Medicine. They were recruited at the conclusion of exams, in the period between December 2008 and May 2009. They were administered a self-assessment questionnaire and an informed consent document which were immediately filled out and then returned. Institutional Review Board Approval was not necessary as established by our central academic office. The questionnaire was previously designed and tested by Giammarioli and colleagues [21]. It consisted of three parts. Part one included personal information such as weight, height, socio-economic indicators, health status and sports activities; this part consisted primarily of closed-ended questions, except for age, weight and height, as described in Tables 1, 2 and 3. Part two assessed dietary attitudes and was designed as a food frequency questionnaire; the foods included were pasta and rice, meat, fish, vegetables, fruit, bread, milk, cheese, eggs, legumes, snacks, alcoholic beverages and brown/whole wheat foods. Part three collected information on the use of supplements and specified eight supplement categories (as shown in Table 4, first column), motivation for use, starting date, purpose of use and satisfaction with use. One of the categories was "sports supplements", which included energy beverages and snacks with sugar, vitamins, minerals, proteins and amino acids; vitamins and minerals sold as tablets or powders were considered as a separate category. The intent of this subdivision was to keep the two typologies of products separate from a commercial point of view, such as the product presentation and the place of purchase, rather than from the nutrient content. Second and third part of the questionnaire were entirely composed of closed-ended questions.

The statistical analysis was performed using SPSS 18.0 software. The descriptive analysis was performed by calculating the means and standard deviations (quantitative data) and frequencies of the answer (category data). Differences were assessed by a one-way ANOVA, Kruskal-Wallis test, the chi-squared test and Fisher's exact test, when appropriate. A value of $\mathrm{P}<0.05$ was considered significant.

\section{Results}

\subsection{Demographics and Lifestyle Characteristics}

Distribution by gender showed that $46.5 \%$ of the participants were male and $53.5 \%$ were female (Table 2). Table 1 illustrates characteristics of the population in terms of age and anthropometric variables. The mean age of the participants was 21.7 years, with a standard deviation of 2.5. In terms of socioeconomic data, $53.5 \%$ had a job activity and $96 \%$ of these had an employment occasional or part-time; many of the employed students $(66 \%)$ worked in sport-related jobs. Data relating to parents' jobs indicated that $90 \%$ of the fathers and $85 \%$ of the mothers were involved in sectors different from sport or health care. A total of $72 \%$ of the students asserted that they did sports at least once a week and $46 \%$ practiced sport three or more times a week. They generally reported being in good health ( $81 \%$ good, $19 \%$ reasonable), but more than half $(53 \%)$ reported mild stress-related disorders.

\subsection{Dietary Supplement Consumption}

A total of $45.1 \%$ of the study population reported the use of dietary supplements. The age of the subpopulation of supplement consumers (SC) was not different from the one of supplement non consumers (SNC). Data showed that males consumed more supplements than females, but the difference between genders was not statistically significant (Table 2). Both indirect socioeconomic indicators (student's or parent's employment) and perceived health did not affect the use of supplements (Table 2). In terms of anthropometric characteristics (weight, height, body mass 
index), the population of $\mathrm{SC}$ did not differ from the population of SNC, except for the mean BMI of SC males $(22,4)$, which was significantly lower than the BMI of male SNC $(22,8)(\mathrm{P}<0.01)$ (Fig. 1). For females, mean BMI of SC was 20,2 and of SNC was 20,6. The mean BMI of total population was 21,4 , that is classified as normal. The BMI evaluation showed that only 9 students were overweight and only 1 was obese.

Table 1. Main Demographic And Anthropometric Characteristics Of The Study Participants (total number 145).

\begin{tabular}{ccccc}
\hline Variable & Minimum & Maximum & Mean & S.D. \\
\hline Age & 19 & 39 & 21.7 & 2.5 \\
Weight & 44 & 94 & 63.8 & 10.5 \\
Height & 152 & 193 & 172.1 & 8.2 \\
(BMI) & 16.90 & 30.84 & 21.45 & 2.47 \\
\hline
\end{tabular}

Table 2. Main lifestyle determinants of the participants and supplement consumers expressed as number and relative frequency (\%)

\begin{tabular}{|c|c|c|c|}
\hline Variable & Category & Participants & Consumers \\
\hline \multirow{2}{*}{ Gender } & Male & $67(46.5)$ & $35(53.8)$ \\
\hline & Female & $77(53.5)$ & $30(46.2)$ \\
\hline \multirow{3}{*}{ Study course } & SUISM & $79(54.9)$ & $38(58.5)$ \\
\hline & MPN Sciences & $45(31.2)$ & $19(29.2)$ \\
\hline & Medicine & $20(13.9)$ & $8(12.3)$ \\
\hline \multirow{2}{*}{ Job activity } & Yes & $77(53.5)$ & $40(61.5)$ \\
\hline & No & $67(46.5)$ & $25(38.5)$ \\
\hline Job & Occasionally & $74(51.4)$ & $38(58.5)$ \\
\hline involvement & Full-time & $3(2.1)$ & $2(3.1)$ \\
\hline \multirow{2}{*}{ Sports job } & Yes & $51(35.4))$ & $29(44.6)$ \\
\hline & No & $26(18.1)$ & $11(16.9)$ \\
\hline \multirow{2}{*}{ Sports practice } & Yes & $104(72.2)$ & $47(72.3)$ \\
\hline & No & $40(27.8)$ & $18(27.7)$ \\
\hline \multirow{3}{*}{$\begin{array}{l}\text { Sports } \\
\text { frequency }\end{array}$} & 1-2 times/week & $37(25.7)$ & $15(23.1)$ \\
\hline & 3-4 times/week & $45(31.3)$ & $19(29.2)$ \\
\hline & $>4$ times/week & $22(15.3)$ & $13(20)$ \\
\hline \multirow{3}{*}{$\begin{array}{c}\text { Father's } \\
\text { employment } \\
\text { area }\end{array}$} & Health & $13(9.0)$ & $5(7.7)$ \\
\hline & Sports & $2(1.4)$ & $1(1.5)$ \\
\hline & Other & $129(89.6)$ & $59(90.8)$ \\
\hline \multirow{3}{*}{$\begin{array}{c}\text { Mother's } \\
\text { employment } \\
\text { area }\end{array}$} & Health & $20(13.9)$ & $6(9.2)$ \\
\hline & Sports & $1(0.7)$ & $1(1.5)$ \\
\hline & Other & $123(85.4)$ & $58(89.2)$ \\
\hline
\end{tabular}

Table 3. Health status of the participants and supplement consumers expressed as number and relative frequency (\%).

\begin{tabular}{cccc}
\hline Variable & Category & Participants & Consumers \\
\hline \multirow{2}{*}{ Perception of health } & Good & $116(80.6)$ & $53(81.5)$ \\
status & Reasonable & $27(18.8)$ & $11(16.9)$ \\
& Not Good & $1(0.7)$ & $1(1.5)$ \\
Chronic diseases & Yes & $12(8.3)$ & $6(9.2)$ \\
& No & $132(91.7)$ & $59(90.8)$ \\
Chronic therapy & Yes & $6(4.2)$ & $3(4.6)$ \\
& No & $138(95.8)$ & $62(95.4)$ \\
Eager for success & Yes & $57(39.6)$ & $25(38.5)$ \\
Therapy for anxiety & No & $87(60.4)$ & $40(61.5)$ \\
& Yes & $1(0.7)$ & $1(1.5)$ \\
& No & $143(99.3)$ & $64(98.5)$ \\
Stress-related disorders & No & $67(46.5)$ & $29(44.6)$ \\
& Mild & $76(52.8)$ & $36(55.4)$ \\
& Serious & $1(0.7)$ & $0(0.0)$ \\
\hline
\end{tabular}

The sport practice and its frequency, in general, did not affect the overall use of supplements except for the male SC who showed a higher consume even if it wasn't significant. However, those who practiced the same sport more than three times a week showed higher supplement consumption than those who did no sport and those who did it once a week, although the difference was not statistically significant.

Considering instead the different categories of supplements, the use of those specific to the sport activity, such as energy beverages and snacks with sugar, vitamins, minerals, proteins and amino acids, was most common in males $(65.7 \%$ of male SC and $13.3 \%$ of female SC) $(\mathrm{P}<$ $0,01)$ and in the subpopulation with the greater frequency of sport activities $(\mathrm{P}<0.01)$. Vitamins and/or minerals (as tablet or powders) were the category of supplements more consumed $(71 \%$ of SC), both by females $(76.7 \%$ of SC) and males $(65.7 \%$ of SC).

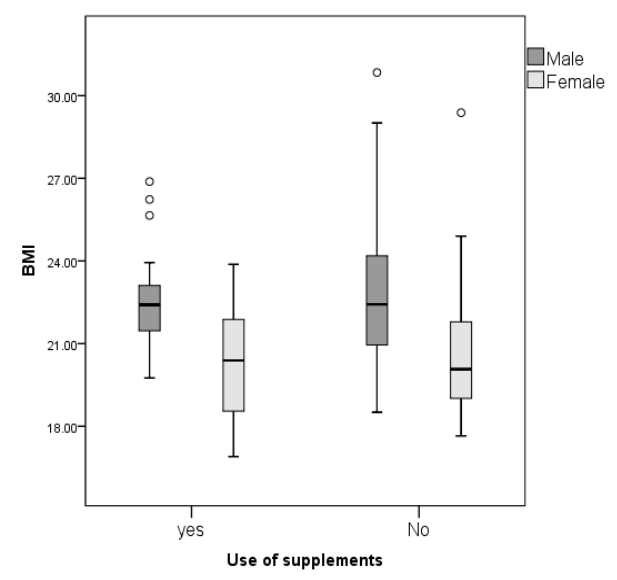

Figure 1. Differences in BMI between male and female supplements consumers and non consumers

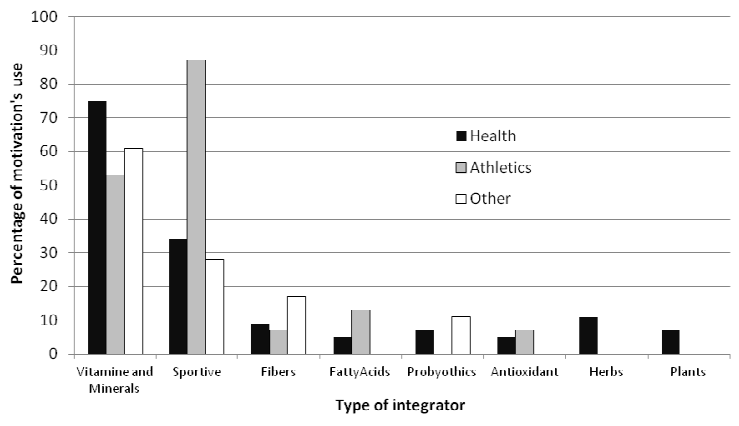

Figure 2. Motivations at the basis of the use of different types of supplements

Other supplements were consumed by fewer than $11 \%$ of the participants. Probiotics and herbs were used exclusively by the female students; fibers, antioxidants and plants were mostly used by females, while fatty acid supplements by males (Table 4).

In regards to the motivations, in general our survey showed that dietary supplements were mainly used for maintaining health and gaining a better sport performance (Fig. 2). Use of vitamins was significantly more common 
among those who took supplements to improve their health $(\mathrm{P}<0.01)$ than among those who took supplements for other reasons, while, as it could be expected, the use of specific sport supplements was primarily motivated by an interest in the athletic performance $(\mathrm{P}<0.01)$. The improvement of sports performance as a motivation for consuming supplements was statistically higher in males $(37 \%)$ than in females $(7 \%)(\mathrm{P}<0.01)$.

The majority of users ( $43 \%$ of females and $20 \%$ of males) stated that they used supplements at the suggestion of a healthcare professional, while almost a third of users $(31 \%$ of males and $27 \%$ of females) had no specific suggestion; other people or factors who influenced the choice of using supplements were friends, chemists and television. Surprisingly, only $3 \%$ of males and no females used supplements based on a trainer's suggestion. The $59.4 \%$ of the SC were at least quite satisfied with the effects of supplement consumption, $25 \%$ reported some satisfaction, and $15 \%$ had no opinion or were not satisfied $(4.7 \%)$.

Table 4. Frequency and type of supplements used.

\begin{tabular}{|c|c|c|c|c|}
\hline Variable & Male & Female & Total & Statistical significance \\
\hline Vitamins and/or minerals (as tablets or powders) & $65.7 \%$ & $76.7 \%$ & $70.8 \%$ & ns \\
\hline $\begin{array}{l}\text { Sports supplements (including energy beverages or snacks with sugar, vitamins } \\
\text { and minerals and proteins or amino-acids) }\end{array}$ & $65.7 \%$ & $13.3 \%$ & $41.5 \%$ & $\mathrm{p}=0.000$ \\
\hline Fibres & $8.6 \%$ & $20 \%$ & $13.8 \%$ & ns \\
\hline Fatty acids & $5.7 \%$ & $3.3 \%$ & $4.6 \%$ & ns \\
\hline Probiotics & $0 \%$ & $13.3 \%$ & $6.2 \%$ & $\mathrm{p}=0.04$ \\
\hline Herbs & $0 \%$ & $16.7 \%$ & $7.7 \%$ & $\mathrm{p}=0.017$ \\
\hline Plants with other nutrients & $2.9 \%$ & $6.7 \%$ & $4.6 \%$ & ns \\
\hline
\end{tabular}

\subsection{Dietary Habits}

All of the subjects declared to consume pasta or rice, they were consumed every day by $64 \%$ of the population, 3 or 4 times a week by $25 \%$, and 1 or 2 times a week by $11 \%$. A similar distribution was observed for bread consumption, although $5 \%$ reported no consumption. Only $19 \%$ of the population reported consuming brown/whole wheat foods. Vegetables and fruit were consumed every day by $61 \%$ of the participants and never by less than $2 \%$. Milk consumption was similar but with a higher percentage of non consumers $(10 \%)$. Meat consumption was reported as 3 or 4 times per week by $50 \%$ of the population, every day by $28 \%$ and 1 or 2 times per week by $20 \%$. A total of $2.5 \%$ of the population did not eat meat. Cheese consumption was similar but with a lower frequency. Also frequencies of consumption of fish, eggs and legumes were similar, with a very low frequency of daily consumers $(<1 \%)$ and higher of no consumers, approximately $10 \%$ for fish and eggs and $19 \%$ for legumes. More than $90 \%$ of the population consumed snacks. Consumption of alcoholic beverages was less common: $55 \%$ of the students reported sporadic consumption 1 or 2 times per week, $30 \%$ did not consume alcohol and only $3 \%$ reported everyday consumption.

There were some significant differences between male and female dietary habits in the total population. The data showed that males consumed more protein, as revealed by the significant differences in the consumption of meat $(\mathrm{P}<$ $0.01)$, eggs $(\mathrm{P}<0.05)$ and legumes $(\mathrm{P}<0.05)$. Males generally consumed more alcohol than females $(\mathrm{P}<0.01)$. There were no significant differences in the dietary habits between the SC and the SNC except for a diet richer in proteins for those who used sports supplements such as amino acid supplements, that is for eating meat more than three times a week $(\mathrm{P}<0.01)$. No other food had a consumption correlated with supplement use, and the eating of snacks and alcohol overlapped between SC and SNC.

\section{Discussion}

Despite of the small sample number, some considerations can be done. The results showed that approximately half of the population studied consumed food supplements. This percentage was similar to those assessed in recent surveys related to adult people in USA [4] and in Italy [6]. It was also similar to the result of the surveys conducted between university students $[16,19,20]$. Socioeconomic indicators, perceived health and anthropometric characteristics didn't show an influence on supplement consumption, only BMI was significantly lower for male $\mathrm{SC}$ than for male SNC while no differences were seen for women. A lower BMI in $\mathrm{SC}$ was also seen in other studies related to American population [15, 16], Swedish [14] and Spanish [8] population. Doing sport is one of the healthy behaviors often associated with the use of supplements[15, 16] but in our study and often in the literature it's true only for males [14, 22].

The dietary behaviors were generally in line with usual Italian diet, and generally dietary habits were comparable between group of SC and SNC, but interestingly, there was an higher consumption of protein among the male consumers of sports supplements, reinforcing an already high-protein diet.

Possible bias could be due to the volunteer recruitment. Approximately $20 \%$ of the students who were informed about the study did not participate. Then, there is an overlapping of the categories defined as sports supplements and vitamin supplements. These supplement categories are commercially different, but the micronutrients involved are 
partially the same. Another bias is due to the high proportion of students involved in sport disciplines and the exclusion of humanistic students.

The awareness of consumption appeared to be high, although a cost-benefit evaluation at the individual and community level may be warranted. Food supplements are not necessary for those in good health, and the dietary supplement market offers both necessary and unnecessary products. As with all dietary products, supplements can be affected by safety concerns. The dose of the supplement is the first crucial point [23], followed by biological [24, 25] and chemical contamination problems [26, 27]. However, supplements can replace lost nutrients, thus playing a valuable role in preventing dietary deficiencies.

The high prevalence of consumption in young and healthy populations may be due to irrational choices. On the other hand, our survey showed that the consumers knowingly chose and identified their specific motivations for taking supplements.

The SC population is increasingly growing and, probably after a long term use, could show differences from a sanitary point of view respect to SNC. For these reasons, a quantitative study that estimates physiological needs and supplement nutrient intakes is warranted; moreover efforts are needed to describe the relationships among dietary needs, genetic makeup, lifestyle and specific needs, such as sports performance improvement.

\section{Acknowledgments}

The authors wish to thank the University of Turin for funding, and then in particular the Scuola Interfacoltà in Scienze Motorie (SUISM), the Mathematical Physical and Natural Sciences Faculty and the Medicine Faculty for their collaboration. We would also like to thank all of the volunteers.

\section{References}

[1] Blendon RJ, DesRoches CM, Benson JM, Brodie M, Altman DE. Americans' views on the use and regulation of dietary supplements. Archives of Internal Medicine 2001;161: 805-810.

[2] Flynn A, Hirvonen T, Mensink GB, Ocke MC, Serra-Majem L, Stos K, Szponar L, Tetens I, Turrini A, Fletcher R, Wildemann T. Intake of selected nutrients from foods, from fortification and from supplements in various European countries. Food Nutr Res 2009;53.

[3] Gardiner P, Woods C, Kemper KJ. Dietary supplement use among health care professionals enrolled in an online curriculum on herbs and dietary supplements. BMC Complement Altern Med 2006;6: 21.

[4] Gahce J, Bailey R, Burt V, Huges J, Yetley E, Dwyer J, Picciano MF, McDowell M, Semphos C, Hyattsville, MD: National Center for Health Statistics. Dietary supplement use among U.S. adults has increased since NHANES III (1988-1994). NHCS Data Brief 2011.
[5] Ock S, Hwang S, Lee J, Song C, Ock C. Dietary supplement use by South Korean adults: Data from the national complementary and alternative medicine use survey (NCAMUS) in 2006. Nutr Res Pract 2010;4: 69-74.

[6] Federsalus. Nielsen survey. 2012.

[7] Marques-Vidal P, Pecoud A, Hayoz D, Paccaud F, Mooser V, Waeber G, Vollenweider P. Prevalence and characteristics of vitamin or dietary supplement users in Lausanne, Switzerland: the CoLaus study. Eur J Clin Nutr 2009;63: 273-81.

[8] Rovira MA GM, Castaner O, Covas MI, Schroeder H; REGICOR Investigators. Dietary Supplement Use and Health-Related Behaviors in a Mediterranean Population. J Nutr Educ Behav 2012;Epub ahead of print.

[9] Skeie G, Braaten T, Hjartaker A, Lentjes M, Amiano P, Jakszyn P, Pala V, Palanca A, Niekerk EM, Verhagen H, Avloniti K, Psaltopoulou T, Niravong M, Touvier M, Nimptsch K, Haubrock J, Walker L, Spencer EA, Roswall N, Olsen A, Wallstrom P, Nilsson S, Casagrande C, Deharveng G, Hellstrom V, Boutron-Ruault MC, Tjonneland A, Joensen AM, Clavel-Chapelon F, Trichopoulou A, Martinez C, Rodriguez L, Frasca G, Sacerdote C, Peeters PHM, Linseisen J, Schienkiewitz A, Welch AA, Manjer J, Ferrari P, Riboli E, Bingham S, Engeset D, Lund E, Slimani N. Use of dietary supplements in the European Prospective Investigation into Cancer and Nutrition calibration study. Eur J Clin Nutr 2009;63: S226-S238.

[10] Nolan A. Audit of supplement use on care of the elderly and rehabilitation wards. J Hum Nutr Diet 1999;12: 453-458.

[11] Richardson MA, Sanders T, Palmer JL, Greisinger A, Singletary SE. Complementary/alternative medicine use in a comprehensive cancer center and the implications for oncology. Journal of Clinical Oncology 2000;18: 2505-2514.

[12] Heikkinen A, Alaranta A, Helenius I, Vasankari T. Dietary Supplementation Habits and Perceptions of Supplement Use Among Elite Finnish Athletes. Int J Sport Nutr Exerc Metab 2011;21: 271-279.

[13] Greiner T. Vitamins and minerals for women: recent programs and intervention trials. Nutr Res Pract 5: 3-10.

[14] Messerer M, Johansson SE, Wolk A. Sociodemographic and health behaviour factors among dietary supplement and natural remedy users. Eur J Clin Nutr 2001;55: 1104-10.

[15] Rock CL. Multivitamin-multimineral supplements: who uses them? Am J Clin Nutr 2007;85: 277s-279s.

[16] Block G, Jensen CD, Norkus EP, Dalvi TB, Wong LG, McManus JF, Hudes ML. Usage patterns, health, and nutritional status of long-term multiple dietary supplement users: a cross-sectional study. Nutrition Journal 2007;6.

[17] Bianco A, Mammina C, Paoli A, Bellafiore M, Battaglia G, Caramazza G, Palma A, Jemni M. Protein supplementation in strength and conditioning adepts: knowledge, dietary behavior and practice in Palermo, Italy. Journal of the International Society of Sports Nutrition 2011;8.

[18] Bui ST, Caine-Bish N, Ha EJ, Lowry-Gordon K. Protein and Creatine Supplementation Habits among University Students. J Nutr Educ Behav 2009;41: 38. 
[19] Olbrich dos Santos KM, de Azevedo Barros Filho A. Use of vitamin supplemets among university students in São Paulo, Brazil. Rev Saúde Pública 2002;36: 250-3.

[20] Szczuko M, Seidler T. [Nutrition mode eavulation among University of Agriculture students in Szczecin in 2006. Part II. Consumption of enriched food and supplements]. Rocz Panstw Zakl Hig 2009;60: 163-6.

[21] Giammarioli S, Boniglia C, Carratu B, Ciarrocchi M, Chiarotti F, Sanzini E. Reliability of a Self-Administered Postal Questionnaire on the Use of Food Supplements in an Italian Adult Population. Int J Vitam Nutr Res 2010;80: 394-407.

[22] George GC, Springer AE, Forman MR, Hoelscher DM. Associations among Dietary Supplement Use and Dietary and Activity Behaviors by Sex and Race/Ethnicity in a Representative Multiethnic Sample of 11th-Grade Students in Texas. J Am Diet Assoc 2011;111: 385-393.

[23] Hanekamp JC, Bast A. Food supplements and European regulation within a precautionary context: A critique and implications for nutritional, toxicological and regulatory consistency. Crit Rev Food Sci Nutr 2007;47: 267-285.
[24] Rossi F, Gaio E, Torriani S. Staphylococcus aureus and Zygosaccharomyces bailii as primary microbial contaminants of a spoiled herbal food supplement and evaluation of their survival during shelf life. Food Microbiology 2010;27: 356-362.

[25] Stocker P, Rosner B, Werber D, Kirchner M, Reinecke A, al e. Outbreak of Salmonella Montevideo associated with a dietary food supplement flagged in the Rapid Alert System for Food and Feed (RASFF) in Germany, 2010. Eurosurveill 2011;16.

[26] Baer I, Emteborg H, de la Calle B. Results from two interlaboratory comparisons on the measurement of trace element contents in food supplements - State of the art of control laboratories in Europe. Food Chemistry 2011;126: 1498-1504.

[27] Plotan M, Elliott CT, Scippo ML, Muller M, Antignac JP, Malone E, Bovee TFH, Mitchell S, Connolly L. The application of reporter gene assays for the detection of endocrine disruptors in sport supplements. Anal Chim Acta 2011;700: 34-40. 